\title{
Teaching Strategies to Get the Tone Right: Making Requests and Gaining Compliance
}

Maria Glass

Language learners invariably struggle with the target language pragmatics, and helping them to understand and use it appropriately is not an easy task for ESL teachers. Specific pragmatic acts, such as requests, involve myriad elements that, despite being inherent to these acts, are quite elusive. No wonder so many ESL teachers feel intimidated and, not surprisingly, end up avoiding dealing with pragmatics in the classroom. This article introduces a strategy-instruction technique that has been proven effective in teaching language learners how to make requests and gain compliance.

La compétence pragmatique dans la langue cible constitue régulièrement un défi aux apprenants de langue; il est également difficile pour les enseignants en ALS de l'expliquer et de faire comprendre son utilisation. Les actes de langage pragmatique spécifiques, comme les demandes, impliquent une myriade d'éléments qui, tout en étant inhérents à ces actes, sont en fait difficiles à cerner. Il n'est pas surprenant que tant d'enseignants en ALS se sentent intimidés et finissent par éviter le sujet en classe. Cet article présente une technique portant sur l'enseignement de stratégies qui s'est avérée efficace pour enseigner aux apprenants de langue comment faire des demandes et comment se faire écouter.

Language learners are highly motivated to appropriately use the target language pragmatics (Tajeddin \& Moghadam, 2012), but it is no secret that usage is difficult for them (Economidou-Kogetsidis, 2011; LoCastro, 2003; Rose \& Kasper, 2001; Schmidt, 1993; Usó-Juan \& Martínez-Flor, 2008). Requests are frequent examples of interlanguage pragmatics failure (Kasper \& Rose, 2002; LoCastro, 2003; Mey, 2001; Wierzbicka, 2003). Determining the level of formality of situations, understanding the power distance and the social relationships, estimating the degree of imposition, and so on are not easy tasks (Economidou-Kogetsidis, 2011; Mey, 2001; Schmidt, 1993; Usó-Juan \& Martínez-Flor, 2008). In addition, there is the need to capture the subtle cultural variances among interlocutors (participants in a conversation) who speak the same target language. Consider, for example, the difference in the use of mitigation devices (words or phrases used to minimize the impact of a speech act) in requests by Canadians and Americans. A simple request such as "Could you please meet with me after class?" could impact Canadians in a way that would be laughable to Americans: Canadians might interpret this request as an order while Americans might see no problem with it. One could reason 
that that is the case because Canadians tend to adopt a more indirect way of communication, while Americans tend to be more direct (Lustig \& Koester, 2006; Robinson \& Zimmermann, 2009). Additionally, the interlocutor's personality, along with circumstantial elements such as mood, affect communication. Making requests is definitely a complex pragmatic act. Nonetheless, we-ESL/EAP teachers-expect our students to competently estimate the level of formality of situations, to understand the power distance and the social relationships, and to gauge the size of imposition, among other factors, despite the fact that the pragmatics of the interlocutor is not a palpable entity with clear-cut boundaries.

In this article, I will share a technique I have developed and have been using in my classroom. The technique consists of engaging interlocutors in dialogues (Dolinski, Nawrat, \& Rudak, 2001; Sanders \& Fitch, 2001), as opposed to making requests in the form of monologues, by using a combination of positive politeness (i.e., appealing to the interlocutor's empathy) and negative politeness (i.e., appealing to the interlocutor's need to feel free to decide what to do; Meyer, 2001; Thomas, 1995). It consistently adopts a foot-in-thedoor strategy that comprises the use of gradual (from meek and tentative to more pushy and assertive) and persuasive speech acts (Burger, Reed, DeCesare, Rauner, \& Rozolis, 1999; Cantrill \& Seibold, 1986; Matusitz \& Breen, 2011; Rodafinos, Vucevic, \& Sideridis, 2005; Vaughn, Firmin, \& Hwang, 2009). It also involves giving the students language gambits (Wood, 2002) they can use in various contexts and with various interlocutors (attending to power distance, social relationships, etc.) and providing them with discourse completion tasks (Kasper \& Rose, 2002; McLean, 2004). The purpose of this teaching technique is to equip students with specific strategies and the language necessary to make requests appropriately and avoid misunderstandings. I have used this strategy-instruction (Taguchi, 2011) type of technique many times in my classrooms (ESL, EAP, and Professional Communication Skills) and workshops and have had very positive feedback.

\section{Procedure}

\section{Step One: Introduction to the Art of Making Requests}

Before introducing the technique, make sure that your students understand that the way people make requests or feel compelled to comply with them may vary because of cultural differences (Abdolrezapour \& Eslami-Rasekh, 2012; Bohns et al., 2011; Holtgraves \& Yang, 1990, 1992; Kim \& Wilson, 1994; LoCastro, 2003; Wierzbicka, 2003). Start by giving the students some situations and asking them to produce requests. It is likely that the students will use formulaic language such as "Could you please" and "Would you please." For example, in situations where students are asked to make requests to their ESL/EAP teacher, they tend to produce requests such as "Could you please make some changes to 
the assignment?", "Would you please fix this mistake?", "Can I have another chance, please?", and so on. It is also likely that your students will make blunt requests in the form of a monologue. As will be discussed later in this article, requests made in the form of monologues are not as effective as those made in the form of dialogues (Dolinski et al., 2001; Sanders \& Fitch, 2001). This is the case because monologues lack interactional features that allow for the use of scaffolding strategies based on the cues brought forth by the requestee.

After the students have produced some requests, role-play the situations with them. As the instructor, play the role of the "requestee" so that the students can be the "requesters." Whenever appropriate, react negatively to their requests and see the students' reactions - they will likely be flabbergasted.

Once your students are convinced that the way they make requests may not be very effective in Canada, go over the request process (see Figure 1) and call the students' attention to the fact that making requests encompasses a combination of complex elements. Discuss the importance of understanding what it is the requester wants ("W") and how it may impact ("SI" or size of imposition) the requestee. Explain that the size of imposition may be exacerbated by unrelated issues (see grey bubble above requestee). For example, a request to change a deadline may disrupt a teacher's already busy schedulethe size of imposition is not small, but the teacher may be willing to comply. However, if the same request is made when the teacher is in a bad mood or is having a bad headache, s/he will very possibly react differently to the request and may refuse to comply.

When the students demonstrate their understanding of the potential impact of a request, discuss the possible cultural differences in making requests

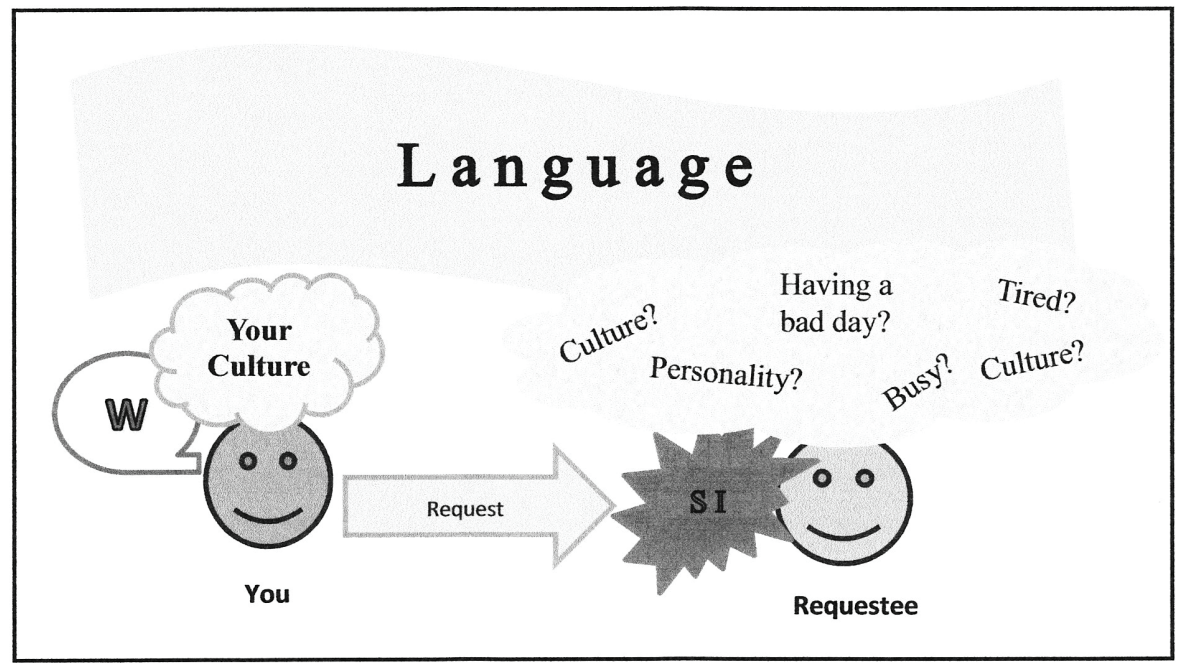

Figure 1. The elements of a request. 
in terms of language use (refer students to the overhanging ribbon in Figure 1 that symbolizes how language permeates the whole process of making requests). Begin by asking the students to reflect on their own culture and then list what could be considered appropriate or inappropriate in terms of requesting. The purpose of this activity is to call the students' attention to their own pragmatics and, in many cases, raise their awareness of it. Then discuss how Canadians, in general, deal with requests in ways different from or similar to the students' approach. Once differences and similarities are established, move to a more subtle and consequently more complicated issuethe fact that English speakers do not necessarily share the same culture.

Talking about cultural nuances and, at the same time, avoiding stereotypes is tricky, so it is safer to focus on language use. Instead of analyzing the Canadian culture, show the students how Canadians tend to use mitigation devices to make requests, and compare the way in which Canadians use these devices with the way other English-speaking people-for example, Americans-do (Lustig \& Koester, 2006; Robinson \& Zimmermann, 2009). The goal is to help the students realize that there might be variances in the way different English speakers make and react to mitigation devices or lack thereof, and that some negative reactions may come as a consequence of interpreting requests as orders or commands. Using several examples, demonstrate how the same request (i.e., the way the request is worded) may be interpreted by an American as a simple request but by a Canadian as an order.

If time permits, encourage students to conduct an informal experiment. Instruct them to show their requests to some English-speaking people and ask them whether they think the requests are appropriately worded or not. The results will likely indicate that people have different opinions about the level of appropriateness of requests. Then brainstorm the possible reasons for this lack of consistency. Properly guided, students are quick to attribute inconsistencies to cultural differences, personalities, and so on. When living in very diverse places, such as the Greater Toronto Area, students are invariably aware that they may come across English speakers from a variety of diverse backgrounds, so it is common to see some learners expressing discouragement ("I'll never get this right..."). If that is the case, it is crucial that students comprehend that misunderstandings have to do with the way requests are worded and how they are performed.

Once it is clear the students have grasped the idea that several elements need to be taken into consideration for a request to gain compliance, share the following technique with the students.

\section{Step Two: The Technique}

Tell students that, before they make a request, it is imperative that they be cognizant of what it is that they want or need, plan how they will communicate their request (whether in writing or in person), and be aware of the possible troubles (size of imposition) that compliance to their request may 
inflict on the requestee. You will see that some students, usually the more mature ones, have little difficulty anticipating sizes of imposition, while others, usually the younger ones, require more practice. Encourage students to practice gauging the size of imposition of requests in small groups, using handouts such as the example in Table 1. After they have explored the situations in their groups, open the discussion to the whole class. It is crucial that the students understand the importance of determining the size of imposition of their requests so that they neither underplay the situation nor overdo the request.

\section{Table 1}

Excerpt of Handout 1: Exploring the Size of Imposition

\begin{tabular}{lllll}
\hline $\begin{array}{l}\text { Who you } \\
\text { are }\end{array}$ & What you want & $\begin{array}{l}\text { To whom you } \\
\text { are making the } \\
\text { request }\end{array}$ & $\begin{array}{l}\text { Medium of } \\
\text { communication }\end{array}$ & $\begin{array}{l}\text { Size of } \\
\text { imposition }\end{array}$ \\
\hline A student & $\begin{array}{l}\text { An extension of an } \\
\text { assignment deadline } \\
\text { (tomorrow) }\end{array}$ & Your teacher & Face-to-face & $?$ \\
A student & $\begin{array}{l}\text { A car ride to the subway } \\
\text { (It's 8 p.m. - it's raining) }\end{array}$ & A classmate & Face-to-face & $?$ \\
\hline
\end{tabular}

The next step is to review their wants or needs and decide whether there is something that requires clarification or an apology. For example, if they need an extension of a deadline, it is possible that something beyond their control occurred, which prevented them from meeting the deadline, or it may be that they simply did not do what they were supposed to. Whatever the reason, it is important that it be communicated to the requestee. The way it is communicated, however, needs to be appropriate so that it appeals to the requestee's empathy (positive politeness).

Show the students how they can word their request: first, they need to acknowledge fault or explain what prevented them from doing what they were supposed to (e.g., "I am afraid I won't be able to meet the assignment deadline, which is tomorrow at the beginning of our class. I have started the assignment but haven't finished it because of some work problems."). Second, the students should acknowledge the trouble (size of imposition) they may be causing to the requestee (e.g., "I understand I may be creating a problem for you and I apologize."). Third, they should offer an alternative action (e.g., "My work problems have been solved and I can focus on my assignment today and tomorrow, so I was wondering if I could submit it by e-mail tomorrow at the end of the day."). By doing so, the requestee may feel relieved not to have to come up with a solution to the problem. In addition, it may move the focus of the conversation to the negotiation of the details of the alternative action, which in turn may lessen the tension that comes from the fact that it is a request in the first place. Fourth, the students should ask if the alternative action is possible (e.g., "Do you think 
this would be possible?"). By asking if it is possible, the requester is using negative politeness, that is, is giving the requestee the opportunity to refuse to comply, which will likely not happen given that negative politeness, in itself, is a technique to gain compliance (Tracy, Craig, Smith, \& Spisak, 1984).

For classroom practice, give the students a handout such as the example in Table 2 (or have the example projected on a screen) to brainstorm language gambits they can use when putting their requests together.

Table 2

Handout 2: Language Gambits

\begin{tabular}{llll}
\hline $\begin{array}{l}\text { Acknowledging fault } \\
\text { (if that is the case) }\end{array}$ & $\begin{array}{l}\text { Showing that you } \\
\text { understand the size } \\
\text { of imposition }\end{array}$ & $\begin{array}{l}\text { Offering an } \\
\text { alternative action }\end{array}$ & $\begin{array}{l}\text { Checking if alternative } \\
\text { action is possible }\end{array}$ \\
\hline $\begin{array}{l}\text { I know I was } \\
\text { supposed to ... }\end{array}$ & $\begin{array}{l}\text { I understand it may } \\
\text { be difficult for you .... }\end{array}$ & $\begin{array}{l}\text { Instead of - maybe } \\
\text { I could ... }\end{array}$ & Is it possible to ...? \\
\hline
\end{tabular}

After the students have demonstrated that they understand the elements involved in making requests (Figure 1), have practiced how to gauge the size of imposition (Table 1), and have been equipped with language they can use (Table 2), it is time to talk about how to perform their request.

When talking about how to perform a request, explain that sequential request strategies, such as the door-in-the-face and the foot-in-the-door techniques, have been proven effective in gaining compliance (Cantrill \& Seibold, 1986). Depending on the level of your students, you may want to focus on the foot-in-the-door technique because the door-in-the-face technique can be challenging for some language learners. The door-in-the-face technique is characterized by initially making a request larger than the intended one with the purpose of obtaining a refusal and then casting the actual request that, because it is smaller than the first, puts the requestee in a difficult position and almost assures compliance (Burger et al., 1999; Cantrill \& Seibold, 1986; Matusitz \& Breen, 2011; Rodafinos et al., 2005; Vaughn et al., 2009). For example, if a requester's actual goal is to have a deadline moved to a day later, s/he requests that it be moved to a week later (larger request). Given the large size of the request, it will probably be refused, and that is the clue for the requester to indicate $s /$ he is willing to settle for a smaller request (in fact, the actual one). The problem with teaching how to use the door-in-the face technique is that it presupposes an initial refusal that may discourage learners of specific cultures. In addition, it requires language that may be too nuanced for many language learners.

The foot-in-the-door technique is the opposite of the door-in-the-face. Instead of starting with an unreasonable request, the foot-in-the-door tech- 
nique consists of a series of persuasion acts aiming at obtaining compliance of small, insignificant initial requests that lead to the actual request (larger than the initial ones). For example, if a requester's actual goal is to have an assignment deadline moved to a day later, s/he could start by asking to submit the assignment an hour later on the due date. Since the size of request is not unreasonable, the requestee may be willing to comply, and by doing so s/he may be allowing for the requester to set a "foot in the door." After the initial compliance, the requester may make his/her actual request, and the likelihood of compliance is high (Cantrill \& Seibold, 1986; Matusitz \& Breen, 2011). Because of its scaffolding nature, from a smaller to a more substantial request, the foot-in-the-door technique is easier for language learners, as they do not feel at risk of losing face as they would with the door-in-the-face technique.

Also important is that students understand the difference between requests that involve dialogues and requests made in the form of monologues (Dolinski et al., 2001; Sanders \& Fitch, 2001). A request that is made in the form of a dialogue has a speech act for each component of the request-use of positive politeness and acknowledgement of fault, demonstration of understanding of the size of imposition, suggestion of alternative action, and use of negative politeness - and these speech acts are performed based on the cues the requestee exhibits during the exchange. For example, a request to move an assignment deadline to a day later could have the following structure:

Student: "I hate to bother you with my problems, but I've had a difficult week at work and haven't been able to finish the assignment that's due at the end of this class."

Teacher: (As the student is justifying and acknowledging his/ her fault, the teacher may show some empathy.)

Student: "I know there's a reason you want the assignments today. You're always so busy! l'm very sorry to disrupt your schedule."

Teacher: (As the student is indicating that $\mathrm{s} / \mathrm{he}$ is aware of the trouble caused by his/her not meeting the deadline, the teacher may continue showing empathy.)

Student: "I really want to finish the assignment, so I was wondering if I could e-mail it to you this evening. Is it possible?'
By apologizing in advance for the bother and acknowledging fault, the requester is appealing to the requestee's empathy (positive politeness).

By showing that $s /$ he is aware of the size of imposition, the requester is again appealing to the requestee's empathy (positive politeness).

The requester now offers an alternative action and asks if it is possible (negative politeness). If the teacher shows willingness to accommodate this alternative action, the requestee will know that s/he has set "foot in the door." 
Teacher: (As the student is demonstrating interest in finishing the assignment and is offering a reasonable alternative to the deadline, the teacher may be inclined to comply.)

Student: "Great! Thank you so much! I will try to send it to you by 8 pm or a bit later, but it'll be before 10-I promise."

Once the requestee lets the requester set foot in the door, the requester may feel it is possible to start negotiating certain elements of the request.

Teacher: (Since the teacher was compliant with the first part of the request, it is unlikely that $\mathrm{s} / \mathrm{he}$ will oppose the student's actual request, i.e., submit the assignment by 10:00 p.m.)

As the example above shows, requests that are made in the form of a dialogue allow for the use of scaffolding strategies that are based on the requester's reading of the requestee's cues (both positive and negative). Conversely, because of its monolithic nature, a request that is made in the form of a monologue offers no possibility of gradual use of strategies.

\section{Step Three: Practice \& Feedback}

Fundamental to the success of this teaching technique is that it be introduced in steps and be followed by abundant practice opportunities. After the introduction of each step, teachers should model the strategies and role-play them in class so that students have a "feel" for the technique. Discourse Completion Tasks (found in McLean, 2004) are excellent role-play starters because they establish a context for the situations.

During role-plays, it is a good idea to label each strategy (e.g., "By saying this, I am gauging the size of imposition," "This is a way of acknowledging fault," "This is how I know I've set foot in the door," "Now, this is what I mean by a request in the form of a dialogue," etc.). This way, the students engage in activities that are both hands-on and cognitively rich.

Also fundamental to the success of this teaching technique is immediate and specific feedback (e.g., "Elena, you did mention the size of imposition but did not apologize for it. How can you do it?"; "Great way of acknowledging your fault, Aziz! By saying that it was your fault, you are informing the requestee that you accept the possible consequences"; "Let's do this again. This time, try making your requests in smaller chunks. Remember that you want to have a dialogue with the requestee, not a monologue"). Whenever a piece of feedback indicates that there is room for improvement, students should role-play the situations again so that they can test the newly suggested strategies and see the results.

Finally, it is crucial that students try the strategies in real-life, beyondthe-classroom interactions; observe whether they are successful or not; detect 
what works and what doesn't; and try to understand why. This way, they can compile their own inventory of strategies to be used in future exchanges.

\section{Acknowledgements}

I would like to thank my friends Adeesha Hack, Andrea Strachan, and Hamid Rezaee for proofreading and giving feedback on the first draft of this article. I would also like to express thanks to the TESL Canada Journal editor and reviewers for their helpful comments and suggestions.

\section{The Author}

Maria Glass is a full-time EAP professor with George Brown College in Toronto, Ontario, Canada. She holds a TESL certificate, a Master's in Applied Linguistics, and a PhD in Linguistics (Pragmatics). Her research interests include Pragmatics, Interpersonal and Intercultural Communication, and Second Language Acquisition.

\section{References}

Abdolrezapour, P., \& Eslami-Rasekh, A. (2012). The effect of using mitigation devices on request compliance in Persian and American English. Discourse Studies, 14(2), 145-163.

Bohns, V. K., Handgraaf, M. J. J., Sun, J., Aaldering, H., Mao, C., \& Logg, J. (2011). Are social prediction errors universal? Predicting compliance with a direct request across cultures. Journal of Experimental Social Psychology, 47(3), 676-680.

Burger, J. M., Reed, M., DeCesare, K., Rauner, S., \& Rozolis, J. (1999). The effects of initial request size on compliance: More about the that's-not-all technique. Basic and Applied Social Psychology, 21(3), 243-249.

Cantrill, J. G., \& Seibold, D. R. (1986). The perceptual contrast explanation of sequential request strategy effectiveness. Human Communication Research, 13(2), 253-267.

Dolinski, D., Nawrat, M., \& Rudak, I., (2001). Dialogue involvement as a social influence technique. Personality and Social Psychology Bulletin, 27(11), 1395-1406.

Economidou-Kogetsidis, M. (2011). "Please answer me as soon as possible": Pragmatic failure in non-native speakers' e-mail requests to faculty. Journal of Pragmatics, 43(13), 3193-3215.

Holtgraves, T., \& Yang, J.-N. (1990). Politeness as universal: Cross-cultural perceptions of request strategies and inferences based on their use. Journal of Personality and Social Psychology, 59(4), 719-729.

Holtgraves, T., \& Yang, J.-N. (1992). Interpersonal underpinnings of request strategies: General principles and differences due to culture and gender. Journal of Personality and Social Psychology, 62(2), 246-256.

Kasper, G., \& Rose, K. R. (2002). Pragmatic development in a second language. Malden, MA: WileyBlackwell Publishing.

Kim, M.-S., \& Wilson, S. R. (1994). A cross-cultural comparison of implicit theories of requesting. Communication Monographs, 61(3), 210-235.

LoCastro, V. (2003). An introduction to pragmatics: Social action for language teachers. Ann Arbor, MI: University of Michigan Press.

Lustig, M. W., \& Koester, J. (2006). Intercultural competence: Interpersonal communication across cultures (5th ed.). Upper Saddle River, NJ: Pearson.

Matusitz, J., \& Breen, G.-M. (2011). Applying communication theories toward designing compliance-gaining techniques in customer dissatisfaction. PASOS, 9(1), 37-46.

McLean, T. (2004). Giving students a fighting chance: Pragmatics in the language classroom. TESL Canada Journal, 21(2), 72-92.

Mey, J. L. (2001). Pragmatics: An introduction (2nd ed.). Oxford, UK: Wiley-Blackwell Publishers.

Meyer, J. R. (2001). Effect of request type and situational features on negative politeness in requests. Communication Research Reports, 18(2), 158-165. 
Robinson, R., \& Zimmermann, S. (2009). A way with words: The influence of language use on national perceptions. Strathy Undergraduate Working Papers on Canadian English, 7, 29-36.

Rodafinos, A., Vucevic, A., \& Sideridis, G. D. (2005). The effectiveness of compliance techniques: Foot in the door versus door in the face. Journal of Social Psychology, 145(2), 237-240.

Rose, K. R., \& Kasper, G. (Eds.). (2001). Pragmatics in language teaching. Cambridge, UK: Cambridge University Press.

Sanders, R. E., \& Fitch, K. L. (2001). The actual practice of compliance seeking. Communication Theory, 11(3), 263-289.

Schmidt, R. (1993). Consciousness, learning, and interlanguage pragmatics. In G. Kasper \& S. Blum-Kulka (Eds.), Interlanguage pragmatics (pp. 21-42). New York, NY: Oxford University Press.

Taguchi, N. (2011). Teaching pragmatics: Trends and issues. Annual Review of Applied Linguistics, $31,289-310$.

Tajeddin, Z., \& Moghadam, A. Z. (2012). Interlanguage pragmatic motivation: Its construct and impact on speech act production. RELC Journal, 43(3), 353-372.

Thomas, J. (1995). Meaning in interaction: An introduction to pragmatics. Harlow, UK: Pearson Education.

Tracy, K., Craig, R. T., Smith, M., \& Spisak, F. (1984). The discourse of requests: Assessment of a compliance-gaining approach. Human Communication Research, 10(4), 513-538.

Usó-Juan, E., \& Martínez-Flor, A. (2008 ). Teaching learners to appropriately mitigate requests. ELT Journal, 62(4), 349-357.

Vaughn, A. J., Firmin, M. W., \& Hwang, C.-E. (2009). Efficacy of request presentation on compliance. Social Behavior and Personality: An International Journal, 37(4), 441-450.

Wierzbicka, A. (2003). Cross-cultural pragmatics: The semantics of human interaction (2nd ed.). Berlin: Mouton de Gruyter.

Wood, D. (2002). Formulaic language in acquisition and production: Implications for teaching. TESL Canada Journal, 20(1), 1-15. 